\title{
GOBERNAR LA CASA Y SALVAR ALMAS: LA RELIGIOSIDAD DE LA DUQUESA DE MEDINA SIDONIA DOÑA ANA DE ARAGÓN (CA. 1502-1556)*
}

\author{
POR \\ JAIME ELIPE ${ }^{1}$ \\ Universidad de Zaragoza
}

\begin{abstract}
RESUMEN
El presente artículo desgrana la religiosidad de la duquesa de Medina Sidonia doña Ana de Aragón (ca. 1502-1556). Casada con los V y VI duques, no solamente dirigió la casa ducal sino también sus pulsiones espirituales. Esto se tradujo en una política de patrocinio de órdenes religiosas, especialmente dominicos y cartujos. También en una constante obtención de mejoras y privilegios eclesiásticos de la Santa Sede, que facilitarían la salvación de la familia y sus criados; asimismo, se intenta identificar cuáles fueron las devociones personales de doña Ana de Aragón. Todo ello indica que nos encontramos ante un modelo de religiosidad algo diferente al observado hasta el momento en el sur hispano, posiblemente debido a su origen aragonés.

PALABRAS CLAVE: Ana de Aragón; Medina Sidonia; religiosidad; devoción; dominicos; cartujos; mujeres; nobleza.

\section{GOVERNING THE HOUSE AND SAVING SOULS: THE RELIGIOSITY OF THE DUCHESS OF MEDINA SIDONIA DONA ANA DE ARAGÓN (CA. 1502-1556)}

\begin{abstract}
This paper describes the religiosity of the Duchess of Medina Sidonia Dona Ana de Aragón (ca. 1502-1556). Married to V and VI dukes, she directed not only the ducal house's politics but also its spiritual drives. This resulted in a policy of sponsoring religious orders, especially Dominican and Carthusian. She worked constantly to obtain ecclesiastical improvements and privileges of the Holy See, which would facilitate the salvation of the family and their servants; likewise, we also try to identify what were the personal devotions of Dona Ana de Aragón. All this indicates that we are faced with a somewhat different model of religiosity than observed so far in the southern Hispanic region, perhaps because of her Aragonese origins.
\end{abstract}

KEY WORDS: Ana de Aragón; Dukes of Medina Sidonia; religiosity; devotion; Dominicans, Carthusians; women; nobility.

CÓMO CITAR ESTE ARTíCULO / CITATION: Elipe, Jaime. 2021. «Gobernar la casa y salvar almas: la religiosidad de la duquesa de Medina Sidonia doña Ana de Aragón (ca. 1502-1556)». Hispania Sacra LXXIII, 147: 153-161. https://doi.org/10.3989/hs.2021.014

Recibido/Received 31-07-2019

Aceptado/Accepted 20-05-2020

\section{INTRODUCCIÓN}

Doña Ana de Aragón (ca. 1502-1556) fue posiblemente una de las nobles españolas más interesantes a la par que desconocida a comienzos de la Edad Moderna. No únicamente por las altas cotas de poder que ocupó como duque-

El presente trabajo ha sido desarrollado gracias al Proyecto PGC2018-094899-B-51. Quisiera agradecer los comentarios de la profesora Laura Malo y de los evaluadores, así como la amabilidad del Archivo Ducal de Medina Sidonia durante mi estancia y del profesor Fernando Cruz.

1 jaime.elipe@gmail.com / https://orcid.org/0000-0001-7863-1804 sa de Medina Sidonia, sino por los distintos avatares que la llevaron a casarse sucesivamente con los dos hermanos don Alonso y don Juan Alonso Pérez de Guzmán. Gracias a sus habilidades de gobierno fue capaz de mantener unidos los estados de los Medina Sidonia en los turbulentos años que transcurrieron a la muerte de Fernando el Católico. Este monarca era su abuelo, de quien descendía por vía de su padre, el arzobispo de Zaragoza don Alonso de Aragón.

Aunque su biografía está todavía por elaborar en profundidad, en el presente artículo pretendemos prestar atención a cómo desarrolló su relación con Dios, esto es, su religiosidad; algo muy personal pero también estrechamente vincu- 
lado al poder. El arranque de su vida espiritual ha de situarse en la educación recibida durante su infancia. Fue en estos primeros momentos de su iniciación en la Iglesia cuando se pueden entender las claves de su modus vivendi de la fe años más tarde; de los que por desgracia no suelen quedar vestigios al respecto (King y Rabil 2007, 31 y ss.). Lecturas de carácter piadoso, libros de horas y ausencia de libros de caballerías es lo que debemos de entender que formaron los primeros escritos que leyó. Al respecto, como introducción a cualquier miembro de la alta nobleza española $-\mathrm{y}$ europea, en definitiva - pueden ser muy ilustrativas las palabras de la profesora Laura Malo $(2018,499)$ :

Las mujeres de la alta nobleza compartían con el conjunto social una relación muy estrecha con los espacios religiosos. La casa, la iglesia y el convento eran lugares en los que no sólo se desarrollaban las prácticas devocionales, sino donde, además, se constituían para ellas entornos de formación, relación y patronazgo. Debido a la privilegiada situación de las damas de la elite, sus vínculos con los ambientes religiosos poseían características especiales. En el interior y exterior del hogar su relación con los espacios de religión quedaba marcada por la especificidad de su posición e influía de forma directa en la creación de devociones particulares.

Siguiendo estas directrices generales, se ha afirmado que las dinámicas religiosas en las distintas cortes nobiliarias que llenaron el espacio hispano se movieron según unos mismos vectores. Es más, según Rafael M. Pérez García, nos encontramos ante unos «nodos de una gigantesca red-circuito" por la que circulaban multitud de personajes y conectaban palacios con claustros. Todo ello en una simbiosis perfecta entre la voluntad de la nobleza y la expansión de distintas órdenes religiosas (Pérez García 2011). A lo largo de las siguientes páginas se pretende conocer cuál fue la religiosidad de la duquesa de Medina Sidonia doña Ana de Aragón y qué influencia tuvo en las pulsiones espirituales de la familia de los Guzmán. Se trató de un personaje de especial importancia dentro de la casa ducal debido a varios motivos: fue esposa consecutiva de dos duques hermanos, evitó el desmembramiento de sus estados y siendo nieta de Fernando el Católico, provenía de un ámbito geográfico muy alejado. Confluyen, por lo tanto, aspectos muy presentes en la historiografía actual - género, redes de poder, patrocinio, devociones- que permiten entender cuál fue la relación de la duquesa y la fe y cómo influyó esta en la vida de su familia y sus criados, además de en la suya propia.

\section{EL CAMINO HACIA LA SALVACIÓN: PATROCINIO Y PRIVILEGIOS ESPIRITUALES}

Efectivamente, la religiosidad de doña Ana de Aragón, desde donde se tiene conocimiento, estuvo fuertemente marcada por el privilegio de su nacimiento y posición. A diferencia de otras nobles de su momento que pasaron a la posteridad con olor de santidad se carece de escritos monográficos sobre su persona, pero parece adecuarse bastante a las características generales que las nobles debían desarrollar. $^{2}$ Esto mismo puede verse en distintos asuntos que

2 Pérez García $(2011,138)$ : «He aquí perfectamente dibujado el modelo de la reina (o noble) devota y espiritual, encuadrado en las desgranaremos a continuación, los cuales vienen marcados por dos aspectos significativos. El primero, el estrechísimo vínculo con la orden de predicadores. El segundo, la acumulación paulatina de exenciones y licencias que mejoraban notablemente su posición personal y familiar en el largo camino hacia la salvación del alma.

Uno de los aspectos más llamativos en la vida religiosa de la duquesa es precisamente la gran devoción y vinculación que tuvieron tanto ella como sus dos maridos con la religión dominica. A pesar de que su abuelo Fernando el Católico tenía especial apego a esta orden ${ }^{3}-$ a diferencia de Isabel, quien se decantaba más por los franciscanos- parece más lógico pensar que hay que buscar el antecedente no en la familia real sino en los Medina Sidonia. Como muchos linajes, los Guzmán quisieron vincularse especialmente con una orden, en este caso la de predicadores. ${ }^{4}$ De alguna manera la actuación de la duquesa no era original, ya que continuaba con la tradición instaurada en la familia desde al menos la década de 1480 (Cruz Isidoro 2011). Al fin y al cabo, entendían que santo Domingo era un Guzmán como ellos y formaba parte de la política familiar potenciar y remarcar una vinculación - totalmente espuria - con el santo evangelizador de los albigenses.

En la misma línea que desarrollaron las principales casas nobles de su época, sobre todo del ámbito castellano, los duques implementaron una política fundacional muy potente. Sanlúcar, capital de sus estados, llegó a albergar nada menos que 15 conventos, de los cuales todos menos dos habían recibido el patrocinio de los distintos duques a lo largo de la Edad Moderna (Atienza López 2008, 159-161).

Aunque en su imaginario eran los V y VI duques de Medina Sidonia los pertenecientes a la estirpe de santo Domingo, consideramos que fue su mujer doña Ana quien impulsó el establecimiento definitivo de los dominicos en los espacios patrimoniales de la casa. Esto hay que entenderlo dentro su implicación en el gobierno que ejerció durante casi toda su vida en los estados de los Medina Sidonia (Elipe 2017). El proyecto provenía ya de la época del II duque, don Enrique (1468-1492) (Vidal Vargas 2018b, 241-242). Sin embargo, a comienzos del siglo XVI seguían los frailes hacinados en la ermita del Espíritu Santo a la espera de recibir unas casas en condiciones para desarrollar su vida con normalidad (Cruz Isidoro 2011, 80). No fue hasta finales de 1528 cuando se puso en marcha la maquinaria ducal para la edificación de una casa a la altura de la orden y de los Guzmán. De tal manera, entre septiembre de 1528 y enero del año siguiente, la duquesa doña Ana de Aragón fue dando un reguero de órdenes a su contador mayor para que librase distintas cantidades a Pedro Díaz Valdivieso, su tesorero y capellán, por los distintos gastos que iba haciendo. Uno de ellos, al fin y al cabo el más importante aunque no fuera en cuanto a importe, fue la compra del solar para el nuevo convento. Para

siguientes coordenadas: virtudes personales, dominio de las propias pasiones, obras de misericordia para con los necesitados, generosidad y donaciones a la Iglesia, y, atención, un entorno cortesano de que se ha convertido en una auténtica colmena de beatas, religiosas, frailes y "hombres devotos". He aquí donde se encuentra una especificidad socio-ecológica esencial de la espiritualidad del Renacimiento».

3 Aunque sigue siendo necesario hacer investigaciones a fondo sobre este asunto, vid. Nieva Ocampo 2013, especialmente p. 70.

4 Otro gran linaje, los Mendoza, hicieron lo propio con los franciscanos, vid. Carrasco Martínez (2000, 240-246). 
ello se gestionó la adquisición de «ocho casas de paja que se toman en la rabal de la mar», puesto que con la demolición de estas infraviviendas se consideraba que se tendría espacio suficiente para la edificación. Aunque solo se tratara de los inicios de la obra, ya hubo en estos momentos un gasto de 100 ducados únicamente para los bueyes comprados y destinados al transporte de la piedra (Cruz Isidoro 2011, 8182). ${ }^{5}$ Hemos de señalar que el momento de la fundación del convento se ha datado un poco más tarde, en 1530, aunque la construcción comenzase un par de años antes (Salas Almela 2011, 199). Tal y como expone la profesora Ángela Atienza, es necesario tener en cuenta que más que un momento concreto de fundación, lo habitual era que existieran varias «fundaciones» (Atienza López 2008, 35-41).

El patrocinio fuerte y claro a favor de los dominicos evidentemente tuvo su correspondencia por parte de la orden. Estos, agradecidos, fueron concediendo un rosario de privilegios a la familia ducal que disfrutaría sobre los miembros y las casas de su religión. El primer privilegio del que se tiene constancia es de mediados de 1535 aunque es de suponer que podría haber habido alguno con anterioridad. En este caso, el general de los predicadores concedía a la duquesa doña Ana la facultad de acceder al monasterio femenino de Sanlúcar con el que también colaboraban estrechamente. A comienzos de 1517, entendemos que doña Ana había hecho firmar a su incapaz marido el duque la confirmación de unas rentas sobre el almojarifazgo a las monjas dominicas. Años más tarde, en 1549, recibirían el patronato del monasterio de Madre de Dios (Cruz Isidoro 2018, 45 y 50). ${ }^{6}$ Más aún, estas entradas podría hacerlas «acompañada de Criadas de buena vida». El favor emitido no tenía límites más allá de los de la voluntad de la noble, pudiendo «entrar las vezes que gustase" y con la posibilidad de hacer noche si lo estimase oportuno. ${ }^{7}$ Al fin y al cabo, el círculo de amistades de las que doña Ana y cualquier noble se rodeaba, terminaban por definirla; estas criadas serían una serie de damas de compañía, cercanas al linaje pero de menor relevancia, así como distintas personalidades amigas (Malo Barranco 2017, 180-181). El hecho de obtener permiso también para ellas ayudaba a reforzar los vínculos con su señora y aumentar su prestigio y posición de autoridad.

El mismo día que el general de la orden fray Juan de Tenario concedía este interesante privilegio otorgaba simultáneamente otro de mayor importancia que venía a subrayar la sintonía de intereses entre los religiosos y los duques, entre los que iba a haber un importante apoyo espiritual a cambio de la gran colaboración material. Un entendimiento perfecto entre las dos ciudades de san Agustín. De esta forma, Tenario brindaba la posibilidad de que el matrimonio pudiera elegir al dominico que más les agradase para tenerlo como confesor, predicador o consejero. El designado tendría la obligación a tales efectos de "venir a sus casas».

Archivo Ducal de Medina Sidonia (en adelante, ADMS), leg. 1002. Doña Ana de Aragón a su contador mayor y oficiales, entre el 6 de septiembre de 1528 y el 2 de enero de 1529 desde Sanlúcar de Barrameda. Sobre los avatares constructivos durante el gobierno de la duquesa doña Ana de Aragón, que escapan al objeto del presente artículo, vid. Cruz Isidoro (2011, 82-83)

6 A este respecto, vid. Graña Cid (2012).

ADMS, leg. 1002. Fray Juan de Tenario, general de la orden de predicadores a doña Ana de Aragón, el 10 de junio de 1535 desde Niebla.
A cambio, la orden obtenía de la pareja algo muy interesante y era que el provincial podría elegir dónde se edificarían los conventos masculinos o femeninos que fundasen los duques (Cruz Isidoro 2011, 82). ${ }^{8}$

Varios lustros más tarde, a comienzos de 1551, el privilegio de visita concedido a doña Ana de Aragón se ampliaba de manera mayúscula. El general de la orden otorgó el acceso a las principales mujeres de la casa - la propia duquesa, sus hijas y su nuera - a los conventos de toda España, tanto femeninos como masculinos. ${ }^{9}$ De esta forma, se venía a redondear una relación de colaboración estrechísima entre los dominicos y los duques, aunque es necesario subrayar que la mano de doña Ana aparece en la documentación como directora de estas relaciones. El punto y final a esta prolongada amistad, continuadora de la que el linaje de Guzmán el Bueno había mantenido de manera más o menos tradicional, solo tendría lugar con el fallecimiento de la duquesa. En esperas de que su marido decidiera qué hacer con ella, sus restos mortales reposaban en el convento masculino de Santo Domingo, cuya primera piedra había colaborado en poner de la manera tan activa que se ha visto hasta aquí (Vidal Vargas 2018a, 227).

Si los duques, especialmente doña Ana, tuvieron un especial interés en cultivar la amistad con los frailes predicadores, los cartujos también disfrutaron de la generosidad de los Medina Sidonia. En 1531, el papa Clemente VII concedió a doña Ana de Aragón la posibilidad de entrar en los monasterios de los frailes de san Bruno con hasta "octo damicellis tuis aut aliis matronis seu mulieribus honestis» para poder oír misa y otros oficios religiosos. ${ }^{10}$ Posiblemente el convento que visitaría la noble con sus damas de compañía sería el de Santa María de la Defensión, en Jerez de la Frontera. Ser prima del emperador debió de facilitar la expedición del breve pontificio.

De cualquier manera la vinculación de los Guzmán con dicha orden no terminó en la entrada y salida de las casas cartujas. Aunque no está documentada la relación que existió y que se desarrolló con el paso de los años en forma de distintas donaciones, puede sostenerse que culminó de alguna manera en 1536. En mayo de dicho año el capítulo general de los cartujos emitía un documento titulado "Carta de Hermandad Despachada en el Capítulo General del horden de la Cartuja a favor de los Señores Duques Don Juan Alonso y Doña Ana de Aragon y Don Juan Claros y Don henrrique sus hijos». ${ }^{11}$ En esta carta los religiosos declaraban su interés en tener presente en sus rezos diarios a la familia du-

\footnotetext{
ADMS, leg 1002. Fray Juan de Tenario, general de la orden de predicadores a los duques de Medina Sidonia, el 10 de junio de 1535 desde Niebla.

9 ADMS, leg. 940. Fray Francisco Romeo, general de la orden de predicadores a doña Ana de Aragón y otras, el 12 de marzo de 1551 desde Sevilla: "concedimus et per totam hispaniam ubicumque nos esse contigerit Monasteria nostra obedientia buiecta ingredi cum Monialibus loqui et refectionenm sumere et spirituali consolatione recreari possitis, dummodo in eisdem non pernoctetis nisi ebdomada sancta paschae et natiuitate domini quod uobis de speciali gratia concedimus».

10 Archivio Segreto Vaticano, A.A., Arm. I-XVII, 2596. Clemente VII a doña Ana de Aragón, el 17 de abril de 1531 desde Roma. Curiosamente, este privilegio lo obtuvo cuatro años antes que el que se ha referido sobre visitar a los dominicos.

11 ADMS, leg. 936. El capítulo general de los cartujos a los duques de Medina Sidonia, el 16 de mayo de 1536 desde la casa mayor de la Cartuja.
} 
cal, lo cual no dejaba de tener gran importancia debido a las numerosas horas dedicadas por estos monjes a la oración.

Se puede concluir que durante el gobierno de doña Ana de Aragón la casa ducal estrechó notablemente sus lazos con las órdenes de predicadores y cartujos. Si bien el apoyo a los primeros fue quizás más activo y visible, eso no significa que no hubiera aportaciones económicas significativas a los segundos. La devoción por estas dos religiones reportó a la familia un gran capital espiritual y simbólico. Hemos de señalar que la duquesa fue la más beneficiada junto con las mujeres de su entorno dentro del conjunto de los Medina Sidonia. ${ }^{12}$ Esto fue debido a que ella llevó la iniciativa en las relaciones con ambas órdenes religiosas.

Como ha quedado expuesto, la vinculación con los dominicos y los cartujos fructificó en una colaboración simbiótica entre la familia ducal y estos. Sin embargo, estaríamos equivocados pensando que la búsqueda y obtención de mejoras espirituales por parte de los Guzmán-Aragón se circunscribió únicamente a estas dos religiones. Para doña Ana existió desde instantes después del matrimonio con el duque don Alonso (finales de 1515) una incesante voluntad de mejorar su posición a la hora de prepararse para rendir cuentas a Dios en el futuro. El primer escalón en este largo camino se puede encontrar ya en fechas tan tempranas como 1517, cuando el papa León $\mathrm{X}$ otorgó a toda la casa la facultad de poder celebrar misa en su residencia, siempre «cum maxima honore et reverentia». Las ganancias espirituales concedidas por el pontífice no quedaban ahí, sino que también obtuvieron el privilegio de poder ser enterrados en tiempo de entredicho. ${ }^{13}$ Aunque todos fueran iguales a los ojos del Padre, una posición social adecuada ayudaba de sobremanera a poder alcanzar la salvación.

Años más tarde, los Medina Sidonia conseguirían de la Santa Sede nuevas bulas. La principal de ellas daba el derecho de poder oír misa en tiempo de entredicho, que se sumaba a la que ya habían recibido para poder ser enterrados en ese tipo de situación. Se añadía también la licencia de poder prescindir del ayuno prescriptivo durante la cuaresma, previo pago de ciertas limosnas. Lo curioso del caso es que a diferencia de la anterior bula que incluía a todos los miembros de la casa, en esta ocasión la nómina era reducida y concreta. Se verían beneficiados los duques, sus hijos y sus respectivas parejas pero también sus sobrinos doña Luisa de Aragón y los marqueses de Llombay. ${ }^{14}$ Siguiendo la línea de

12 La noble, como hemos podido observar, sigue el modelo de las dos casas nobiliarias estudiadas por Laura Malo Barranco $(2018,499)$ : «Fuera de los muros de la casa, las mujeres de la nobleza gozaban de toda una serie de ventajas en el acceso a instituciones religiosas y aprovechaban su preeminencia para ejercer gran cantidad de acciones piadosas y fundacionales relacionadas a los lugares de culto».

13 Durante el período en el que una autoridad eclesiástica imponía el entredicho estaba prohibida la asistencia a los oficios divinos, la sepultura y la administración de algunos sacramentos. ADMS, leg. 934. León $\mathrm{X}$ a don Alonso Pérez de Guzmán y doña Ana de Aragón, el 30 de julio de 1517 desde Roma.

14 ADMS, leg. 936. Clemente VII a don Juan Alonso Pérez de Guzmán y doña Ana de Aragón, el 18 de junio de 1532 desde Roma: «Bulla. Trasumpto autorizado. De la Bulla de la Sanctidad de Clemente VII en que dispenso y commuto el ayuno Quadragesimal y otro estauido por la Yglesia en limosnas a los Señores Duques Don Juan Alonso y Doña Ana de Aragon su muger, Don Pedro y Doña Mencia Condesa de Ureña, Doña Maria Giron hija de esta, Don Fernando y don Alonso de Aragon, Don Francisco de Borja y Doña Leonor de Castro, Marqueses de Lom- preocupación de doña Ana por obtener todo tipo de ventajas espirituales, también parece que fue ella la promotora de la petición y quien consiguió gestionar su obtención. No en vano, la secretaría de Clemente VII añadía que «quod nos vestris deuotis supplicationibus inclinati vobis qui vt assentis ex illustri Regum \& magnatum prosapia originem». Evidentemente, ninguno procedía de sangre real a excepción de doña Ana.

La última de estas bulas obtenidas de Roma que jalonaron el gobierno de doña Ana de Aragón es muy significativa, ya que suponía la culminación de convertir la casa de los Guzmán en un auténtico centro espiritual salvífico para sus moradores. Al fin y al cabo, era un ingrediente más del modelo espiritual que se esperaba de la nobleza ibérica y tenían que obrar en consecuencia, tal y como era corriente en casi todos los linajes (Pérez García 2011). Clemente VII concedió en julio de 1532 la gracia especial de que cualquiera que visitase la capilla ducal obtendría indulgencia si se encontraban expuestas las reliquias del titular de la festividad del día en concreto. ${ }^{15} \mathrm{Ha}$ de tenerse en cuenta que los límites entre lo privado y lo público eran muy difusos y aunque los duques se retirasen a la capilla a rezar en privado, también se abría a todo tipo de personas (familiares, servicio, amistades, visitas...) en otros momentos determinados (Malo Barranco 2017, 179).

Un aspecto quizás más mundano pero de notable impacto social fue su indispensable colaboración para lo que después sería el sevillano convento de Jesús. En la parroquia de san Vicente se había creado por "algunas devotas mujeres» una casa de recogimiento para sacar a mujeres de la prostitución y reformarlas. Fue doña Ana quien consiguió mover influencias y lograr que, conjuntamente con el príncipe Felipe, Paulo III favoreciera esta naciente institución con una bula en 1540 (Ortiz de Zúñiga 1796, 381). Si bien no entró en vigor hasta 1551, momento en el que se adquirieron las casas necesarias, su contribución fue fundamental por sus buenas relaciones con la Corte y con la Santa Sede.

Para finalizar el gobierno de la vida espiritual por parte de doña Ana de Aragón, señalaremos un aspecto bastante interesante. Viene a remarcar la continuidad de su aparente omnipresencia en los asuntos de carácter religioso que marcaban el tiempo en la casa ducal. Estuvo plenamente activa a la hora de ejecutar los detalles de los bautizos de sus hijos, de los que se conservan tres testimonios. El primero es el del bautismo de doña Leonor de Guzmán, a principios de 1534 , por el que se pagaron en concepto de ofrenda diez ducados. ${ }^{16}$ Dos años más tarde se dieron ciertos gastos con motivo del nacimiento de don Enrique de Guzmán; si bien era un conglomerado de maravedíes por su bautismo y aspectos relativos a su crianza, doña Ana firmaba el pago de otros diez ducados. En esta ocasión, el duque don Alonso también indicaba a su tesorero que se librasen distintas can-

bay y Doña Luisa de Aragon, concediendoles tambien que pudiesen oir misa en tiempo de entredicho".

15 ADMS, leg. 936. Clemente VII el 12 de julio de 1532 desde Roma: "ganen diez años de perdon otras tantas quarentenas todos los fieles de ambos sexos que arrepentidos y confesados visitasen desde Uisperas hasta otro dia puesto el Sol la Capilla en que los Señores Duques de Medina Sidonia tubieren colocadas varias Reliquias de Santos en festividades del Año, y de cada una de las Reliquias».

16 ADMS, leg. 936. Doña Ana de Aragón al contador mayor, el 18 de enero de 1534 desde Sanlúcar de Barrameda. 
tidades por estos motivos. ${ }^{17}$ En 1537 se repitió la operación entre los dos duques de ordenar que distintos particulares pudieran cobrar un variopinto número de cantidades con motivo del nacimiento de doña Ana Agustina de Guzmán. ${ }^{18}$ Aunque apareciera el $\mathrm{V}$ duque don Alonso ordenando pagos, es evidente que no fue él quien dio las directrices al respecto debido a su incapacidad mental más que demostrada.

\section{Pulsiones PERSONAles: ENTRE SANTOS Y El CLAUStRo}

Si la biografía requiere en ocasiones un esfuerzo mayor por intentar comprender al objeto de estudio y cuáles fueron sus actuaciones y decisiones, intentar acercarse a las devociones particulares suele ser tarea francamente complicada, no siempre hay respuestas claras y estas tienen que ser tomadas con cautela (Pennman 2013). A no ser que existan escritos de carácter personal en forma de epístolas o diarios, la tarea de conocer cómo doña Ana concretó su fe en el día a día puede llegar a ser imposible. Ahora bien, por paralelismo o pequeños indicios se puede trazar un panorama general. En el caso que nos ocupa tal sucede, por lo que únicamente podremos apuntar algún aspecto devocional completo, pero que no agota para nada esta vía de investigación. Teniendo en cuenta que vivió con sus padres en Zaragoza hasta que se decidió su matrimonio, es lógico pensar que las devociones familiares pudieron influir en las suyas propias. ${ }^{19}$ De su propio padre, el arzobispo don Alonso de Aragón, es conocido que tenía especial devoción por la Virgen María, san Juan Bautista y san Juan Evangelista, a quienes quiso dejar labrada una capilla a su muerte (Elipe 2020). Por lo que atañe a doña Ana de Gurrea, su madre, no está claro que tuviera una devoción acusada por algún santo en concreto. ${ }^{20}$ Dentro del abigarrado elenco de objetos de culto que se inventariaron a su muerte, parece que las preferencias de doña Ana de Gurrea se inclinaban por la Virgen -en distintas advocaciones-, la Verónica y santa Ana. ${ }^{21}$

Más allá del fervor que pudiera sentir por las religiones dominica y cartuja, únicamente se cuenta con un testimonio fehaciente en el que juntamente con su segundo marido don Juan Alonso Pérez de Guzmán hicieron algunas donacio-

17 ADMS, leg. 936. Don Alonso Pérez de Guzmán y doña Ana de Aragón a Pedro Díaz de Valvidieso, el 10 de enero de 1536 (y otras fechas del mismo año) desde Sanlúcar de Barrameda.

18 ADMS, leg. 936. Don Alonso Pérez de Guzmán y doña Ana de Aragón a Pedro Díaz de Valvidieso, el 10 de septiembre de 1537 desde Sanlúcar de Barrameda.

19 Consideramos que la formación espiritual recibida en la infancia marcaría a doña Ana, si bien no tenemos ninguna prueba fehaciente. Paul M. Bacon $(2008,991)$ en su estudio sobre el elector de Sajonia Federico el Sabio también sitúa la principal devoción del noble alemán en su infancia.

20 Archivo Histórico Nacional (en adelante, AHN), Sección Nobleza, Osuna, leg. 538, doc. 10. Testamento de doña Ana de Gurrea, el 5 de junio de 1523 en Zaragoza. Las invocaciones en el testamento únicamente son a Cristo, la Virgen y la corte celestial, algo muy corriente. Por otro lado, más que a santos en concreto sí parece dar la impresión de que tenía especial cariño a algunas iglesias de Zaragoza (San Agustín o San Nicolás), pero nada más se puede concretar por su testamento u otros documentos a los que hemos tenido acceso.

21 Como decimos, es un campo por tratar a fondo. Estas pinceladas preliminares se extraen de Archivo Histórico de Protocolos Notariales de Zaragoza, Domingo Español, sig. 3776, ff. 26r. Inventario de los objetos de doña Ana de Gurrea y testimonio de su fallecimiento, el 29 de enero de 1528 en Zaragoza. nes al monasterio de Guadalupe, una reja cubierta de plata y ciertas piezas para el coro. Entre 1536 y 1537 pagaron unos 41 ducados por estos encargos a diferentes artesanos sevillanos. ${ }^{22} \mathrm{~A}$ pesar de que un número significativo de los beneficiados por la Virgen eran del ámbito sureño, no se ha podido encontrar ninguna vinculación directa con los Medina Sidonia; aunque devotos de Guadalupe, los duques no habrían recibido extraordinarios dones que justificasen este desembolso o ser inscritos en el listado de milagros (Crémoux 2015, 212-281). Sí que parece que en alguna ocasión los duques, o al menos la duquesa, pasaba alguna temporada en el monasterio (Gómez Fernández 2017, 162). Por otra parte, los Guzmán custodiaban una serie de reliquias de santos en su capilla privada, que durante las festividades de sus antiguos dueños exponían para su veneración. Conocer el origen de dichas reliquias y su adquisición sería de gran ayuda para poder precisar las devociones de la duquesa o su segundo marido; por desgracia no hemos sido capaces de localizar nada más allá de la noticia de la bula pontificia que otorgaba indulgencia a quien las visitase..$^{23}$

Las devociones de doña Ana de Aragón permanecen un tanto inciertas hasta aquí a partir de la documentación de la casa ducal..$^{24}$ La única que se puede sostener con bastante seguridad es la devoción de la aristócrata por su santa epónima. Cada 26 de julio, la duquesa iba en peregrinaje a Santa Ana, situado en Triana (Gómez Fernández 2017, 107). Es por ello por lo que tenemos que buscar otras vías de acercamiento. Nuestra propuesta es hacerlo por comparativa de su entorno cercano que pueda ser mejor conocido, para trazar hipotéticas influencias devocionales en su familia. ${ }^{25}$ Es por ello por lo que centraremos nuestra atención en la estrechísima relación que existió con su sobrina doña Luisa de Borja - futura duquesa de Villahermosa-. En algún momento indeterminado entre 1520 y 1521 murió doña Juana de Aragón, duquesa de Gandía y hermana de doña Ana. ${ }^{26}$ Debido a la delicadísima situación política que se vivía en el reino de Valencia a causa de los agermanados, el III duque de Gandía decidió poner a salvo a su familia enviándola a lugares de confianza. De esta manera, Francisco y Luisa marcharon a Zaragoza con su tío el arzobispo don Juan de Ara-

22 ADMS, leg. 936. Don Juan Alonso Pérez de Guzmán a Pedro Díaz Valdivieso, capellán y tesorero de los duques, el 19 de septiembre de 1536 desde Sanlúcar de Barrameda: «pero dias valdevieso mi capellan e tesorero. yo vos mando que de los mrs de vuestro cargo deste año deys a geronimo monçon mi criado ocho mill e dozientos e veynte mrs los quales ha de aver para que los de y pague en la cibdad de sebilla a hernando galban presbitero vezino de la dicha cibdad el qual los obo de aver a cumplimiento de diez mill e trezientos y treynta en nebe mrs que montaron ciertas hechuras de ciertas pieças del coro quel hizo para la Señora duquesa mi señora y por ciertas cosas que se conpraron para la reja de plata que yo mande hazer para mi senora de gadalupe». En folios siguientes hay otros gastos menores, principalmente de la reja y los distintos artesanos que intervinieron en su manufactura.

${ }_{23}$ ADMS, leg. 936. Clemente VII el 12 de julio de 1532 desde Roma.

24 Sí que parece haber pistas de su nieto, el que sería VII duque don Alonso Pérez de Guzmán el Bueno, quien encargó en torno a 1576 una serie de retratos de varios dominicos ilustres para su propio disfrute en el palacio de Sanlúcar. Al respecto, vid. Cruz Isidoro (2002, 357-364).

25 Similar se ha realizado con el caso del arzobispo don Alonso de Aragón, su padre; para ello, Jaime Elipe (2020).

26 No existe una fecha exacta que cuente con un aval documental, así lo expresa Francisco Pons Fuster $(2012,168)$. 
gón y allí permaneció la niña hasta que en 1522 su bisabuela la reclamó y marchó a Baza con ella. La duquesa doña Ana de Aragón terminó pidiendo a su sobrina para criarla en la corte sanluqueña, algo que su cuñado el duque don Juan de Borja aceptó. Así, en la primera mitad de 1523, tía y sobrina se encontraban en la residencia principal de la casa de Guzmán (Nonell 1892, 31-46). Gracias al testamento que dictó doña Luisa en 1554, pueden seguirse ciertas continuidades con lo que tuvo que ser el clima espiritual en Sanlúcar cuando se crió allí de niña. Sus principales devociones fueron san Francisco de Asís, los santos Luises - obispo y rey de Francia-, los santos Juan Evangelista y Bautista, santo Domingo de Guzmán, san Martín y las santas María Magdalena, Catalina e Inés (Morte García 2008-2009, 490).

Entendemos que así puede observarse cómo distintas tradiciones devocionales de "sus familias» confluyeron en doña Luisa de Borja, en quien se mezclaron variados santos favoritos y preferencias de sus distintos antepasados. San Francisco y santa Inés son fácilmente relacionables con su familia paterna, los Borja, fieles devotísimos del santo de Asís y especialmente sus mujeres, vinculadas al convento de Santa Clara en Gandía. Ahora bien, son de particular interés santo Domingo de Guzmán, santa Catalina (de Siena), san Juan Evangelista y san Juan Bautista. Los dos primeros pertenecen a lo que podría identificarse como los santos propios de los Medina Sidonia, de quienes ya ha quedado sobradamente demostrados sus estrechos vínculos con la orden dominica. ${ }^{27}$ El evangelista y el primo de Cristo formaban parte de la devoción personal de su abuelo el arzobispo don Alonso, santos de gran popularidad. Por lo tanto, puede establecerse una continuidad entre su familia materna y «de acogida» en la figura de doña Luisa, que necesariamente pasa por su tía la duquesa doña Ana de Aragón. No consideramos descabellado señalar a esta como la persona que le transmitió la devoción por esta pareja de santos, pertenecientes tanto a su tradición familiar propia como a la de la casa que gobernaba. ${ }^{28}$

En último lugar, queremos señalar un aspecto interesante de la duquesa respecto a la dirección de las vocaciones monásticas en su familia. Hemos de llamar la atención que al ser doña Luisa hermana de san Francisco de Borja y haber

27 Años más tarde, el VII duque encargaría las pinturas anteriormente mencionadas en las que aparecen ambos santos, vid. Fernando Cruz Isidoro $(2002,358)$ : "Volviendo a las pinturas de Pereira, el documento declara que los dominicos representados fueron el fundador Santo Domingo de Guzmán, Santo Tomás de Aquino, San Vicente Ferrer, San Pedro Mártir, San Antonino y Santa Catalina de Siena».

${ }_{28}$ San Luis XI y san Luis de Tolosa fueron sus santos personales, este segundo por haber nacido en el día de su festividad. Más difícil es encontrar el motivo de san Martín o incluso el de María Magdalena. Bien pudiera ser, si bien no es más que una conjetura de la que no hemos podido hallar base documental, que esta última proviniese también de la duquesa doña Ana de Aragón. Podría encontrarse un posible origen en un plausible cargo de conciencia de doña Ana por sus muy irregulares matrimonios y la más que probada ilegitimidad de su primer hijo, don Juan Claros. Por ser la pecadora - de carácter sexualarrepentida y redimida por antonomasia desde que así elaborase el personaje el papa Gregorio Magno, podría entenderse que la duquesa sintiera algún tipo de afinidad o de identificación. Puede aventurarse que doña Ana cometió adulterio durante su primer matrimonio con su cuñado, el que sería su segundo marido y VI duque don Juan Alonso. A esto hay que añadir la gran devoción que tuvo la santa a finales de la Edad Media en Europa, ya que se la relacionaba con la posibilidad de recuperar la virginidad, según sostiene Katherine L. Jansen (2000). Sobre la construcción de la Magdalena, vid. Anselm Husftader (1969). pasado a la posteridad como «la Santa Duquesa», muchos aspectos de su biografía han de ser tomados con precaución. Que su tía y abuela fueran monjas en Gandía evidentemente tuvo que dejar su impronta en doña Luisa, pero no se ha de perder de vista que permaneció en Sanlúcar hasta 1541, momento en el que accedió a casarse con don Martín de Aragón, pariente lejano y futuro duque de Villahermosa. Es decir, estuvo conviviendo durante casi veinte años con los duques, quienes la trataron en todo momento como a una hija más; a tal punto llegó su amor que decidieron dotarla por su cuenta como si fuera parte de su descendencia. Su padre, el duque de Gandía, quería que su hija saliese del siglo en vez de casarse, algo habitual en las mujeres de la familia Borja. Así lo expresaba en su testamento en 1538:

Item donamos y legamos a Doña Luisa de Borja, nuestra amada hija y de la ilustre Duquesa Doña Juana de Aragón, primera mujer nuestra, cien ducados de oro por parte y por legítima, y por todo y cualquiera otro derecho que aquella tenga en nuestros bienes $y$ pretenda tener $\mathrm{y}$ pertenecerla pueda en cualquiera manera, como sea nuestra voluntad que aquella sea monja, así como lo son las otras hermanas suyas e hijas nuestras en el dicho Monasterio de Santa Clara de la dicha nuestra Villa de Gandía, o en cualquiera otro monasterio que la muy ilustre Doña Ana de Aragón, Duquesa de Medina Sedonia, tía suya materna, querrá y mandará, estando empero, la dicha Doña Luisa, hija nuestra, a todo lo que de ella la ilustre Duquesa ordenará y mandará como a madre y señora suya, en casa de la cual hoy está (Sanctus Franciscus Borgia ... $1894,86) .^{29}$

Fueron sus tíos maternos, el arzobispo don Hernando de Aragón y doña Ana quienes le mostraron que era más conveniente al servicio de Dios su matrimonio que acabar en un convento. Si esto fue realmente así, no cabe duda de que fue en contra de los deseos del duque don Juan de Borja, a la vista de su testamento. Si en algún momento llegó a tener doña Luisa vocación verdadera, esta fue bastante pasajera: de lo que no cabe duda es que tiempo después fue enormemente magnificada, adornada con cartas completamente espurias. ${ }^{30}$ Quizás la jovencita doña Luisa tuvo cierta vocación por la vida del claustro y la penitencia. ${ }^{31}$ Sin embargo, los testimonios proporcionados por autores como Muniesa o Nonell fueron descaradas invenciones, que hasta

29 Testamento de don Juan de Borja III duque de Gandía, el 28 de febrero de 1538 desde Gandía.

30 Un buen ejemplo es la supuesta epístola de doña Ana de Aragón al duque de Gandía (Nonell 1892, 54-55): «En una cosa me suele hacer enojar, y la riño, y quisiera que vuestra Señoría con su autoridad paternal la riñese tambien y un poco me ayudase, porque no bastamos los que somos aquí para moderarla segun conviene: es á saber, que se menoscaba la salud, y se le conoce muy bien, con el demasiado retiro y mortificaciones, más de lo que convendría y puede soportar. Ya le digo que yo he de dar cuenta de ella, como de cosa encomendada, y no se lo puedo todo sufrir. Yo por eso y por otras cosas estoy en que ella dura en aquellos pensamientos de monja de Gandía: mas ya le digo que por ahora vuestra Señoría y mi hermano el Arzobispo no son de este parecer, ni yo tampoco; y así que no piense hacer ya vida de monja, ni quiera debilitarse en fuerzas y salud, y otras cosas que se me ofrecen; y le pongo escrúpulo. Como es temerosa y rendida, se enmienda; mas presto vuelve á su inclinacion, y la perseguimos. De todo se sirva Dios que la crió».

31 Al respecto, resulta de gran interés aunque centrado en otro arco cronológico el trabajo de Sara Cabibbo $(1998,42)$. 
adelantaron la fecha de su nacimiento para poder aumentar más aún la nómina de virtudes de la noble (Morte García 2008-2009, 484-485). ${ }^{32}$

En definitiva, tomando el extracto del III duque de Gandía puede observarse la posibilidad de que doña Luisa ingresara en un convento siguiendo el ejemplo de buena parte de las Borja, quienes hicieron lo propio en Santa Clara de Gandía (Pons Fuster 2016, 272). Probablemente, doña Ana de Aragón tuvo una relevancia fundamental para disipar - ¿quizás también junto con su hermano, el arzobispo de Zaragoza don Hernando? - los proyectos de su cuñado el duque de Gandía. Al fin y al cabo, habiendo nacido en 1520 y a causa de la muerte de su madre poco después, la única figura materna con quien contó doña Luisa fue la duquesa de Medina Sidonia. Y esta, aunque profundamente devota, no parece que tuviera especial apego por la vida claustral. Por ello mismo, no sería descabellado que no aceptase que su sobrina-hija pudiera acabar en un convento pudiendo gobernar una casa nobiliaria como ella misma había hecho.

Esto mismo nos conduce a una reflexión bastante interesante. En el artículo anteriormente mencionado del profesor Pérez García, una de las ideas principales que se defiende era la conexión espiritual de los distintos nodos nobiliarios así como la profusión de religiosos notables dentro de los principales linajes andaluces (Pérez García 2011, 139 y ss.). ${ }^{33}$ Más aún, considera que "no se trata de casos "especiales", sino normales»; algo que afectaría a "todas las grandes familias de la nobleza andaluza y, nos aventuramos a proponer, española» (Pérez García 2011, 147). Precisamente en la familia de doña Ana de Aragón se dio el caso opuesto. Ninguno de sus hijos ingresó en religión; más aún, parece claro que la duquesa hizo todo lo posible, por apartar a su sobrina doña Luisa de esa supuesta vocación que mantuvo en su juventud a la que su padre el duque de Gandía la empujaba. Si puede decirse que existió un modelo andaluz - extensivo a zonas extremeñas y del reino toledano-, consideramos que la noble impuso en cierta medida una estrategia propia. A falta todavía de más estudios sobre las mujeres en la nobleza aragonesa, por ahora coincide con lo que ha demostrado la profesora Malo Barranco para los linajes de los Híjar y Aranda: un número reducidísimo de mujeres fueron destinadas al claustro (Malo Barranco 2018, 256 y ss.). Tomando ambas tesis, podría sostenerse que al provenir de un ámbito distinto -el aragonés-, doña Ana de Aragón instauró un modelo devocional un tanto diferente en los Medina Sidonia, rompiendo así con la costumbre general del sur hispano. Como contrapunto dentro de la propia familia de sus dos maridos, puede ser ilustrativo el ejemplo de su cuñada, doña Mencía de Guzmán -hija del primer matrimonio del III duque de Medina Sidonia y esposa de Pedro Girón-. Esta

32 Teniendo esto mismo en cuenta, no se casó con 28 sino con 21 años. Las fechas ofrecidas en este artículo se refrendan fácilmente con el testamento de la abuela materna de doña Luisa, quien «encargo al dicho señor arçobispo [don Juan de Aragón] que al tiempo del matrimonio de la dicha dona luysa de borja le quiera dar y entregar todos los bienes mobles de atabios de casa y plata y dineros contados que yo tubiere y se hallare al tiempo de mi muerte». Esto era así porque evidentemente, una niña de tan apenas tres o cuatro años no podía pensar en ser monja, vid. AHN, Sección Nobleza, Osuna, leg. 538, doc. 10. Testamento de doña Ana de Gurrea, el 5 de junio de 1523 en Zaragoza.

33 El autor se centra en varios linajes de importancia como condes de Belalcázar o los duques de Béjar. aparece en la Vida de doña Ana Ponce de León como mujer muy preocupada por darle a su sobrina doña Ana Ponce de León una educación cristiana "total», rayana en la vida conventual: esto mismo colaboró activamente en la perfección de dicha señora años más adelante. ${ }^{34}$

\section{Conclusiones}

A lo largo de estas páginas hemos intentado asomarnos a un caso concreto de religiosidad femenina encarnado por la duquesa de Medina Sidonia doña Ana de Aragón. Esto se ha hecho atendiendo al período aproximado de 30 años desde su primer matrimonio en 1515 hasta su deceso, momentos de los que más información arrojan las fuentes. Varios aspectos destacan especialmente en su figura.

El primero de ellos no es otro que su decidido apoyo a las órdenes religiosas, especialmente a dominicos y cartujos. De estas dos destaca la primera, con la que la casa de Medina Sidonia estaba estrechamente vinculada, queriendo reforzar los falsos lazos familiares con santo Domingo de Guzmán, además de las relaciones mantenidas desde hacía varios decenios tras la ayuda del II duque. Se llevaron de esta manera importantes desembolsos económicos para poder realizar fundaciones conventuales; los duques recibieron a cambio un decidido apoyo en forma de capital humano y espiritual. Aunque importante, algo menor en comparación fue la relación mantenida con los cartujos quienes no dudaron en ofrecer sus oraciones a los Guzmán si bien desconocemos las contribuciones materiales a estos.

El segundo, siguiendo las pautas esperables de una persona de su condición, fue la acumulación de mejoras espirituales por parte de la Santa Sede. Fueron de varios tipos: desde privilegios para sortear los abundantes períodos de entredicho habidos en la modernidad a beneficios concretos para personas concretas, aunque también para la casa en su conjunto. Este último aspecto lo consideramos muy relevante ya que ayudaba a jerarquizar en dos direcciones el poder de los Medina Sidonia - y de doña Ana, gestora principal de estas bulas-. En primer lugar, internamente, diferenciando a los miembros de la familia más cercanos como los duques y sus hijos, del resto de familiares y criados. En segundo lugar, externamente, ya que únicamente residir en el palacio generaba una serie de facilidades a la hora de alcanzar la salvación del ánima. Más aún, la casa residencial tenía algunos rasgos decididamente marcados para intentar convertirse en una especie de templo-palacio, gracias a las indulgencias que se podían recibir al visitar sus reliquias en determinados momentos del año. Todo ello, conviene no olvidarlo, se pudo obtener gracias a una estrecha relación con el papado, que posiblemente se veía mejorada por la amistad que tenían los duques con la familia imperial.

Tercero, el aspecto devocional de doña Ana de Aragón es complejo aunque se han explicado las claves principales. Está fuera de toda duda la atención que dedicaron ella y su

34 Martín de Roa $(1604,9)$ : «Encargose de su criança la Duquesa Doña Mencia, hermana del Duque de Medina Sidonia, Don Enrrique, y muger de Don Pedro Giron Conde de Vreña, tia suya: y lleuola consigo al Arahal, grande y principal villa del Ducado de Ossuna; donde con mui loable y Christiana enseñança formaua la Duquesa los tiernos años de la niña, y afinaua sus costumbres: ayudandole para todo la blandura de natural, y suabuidad de condicion, que Dios le auia dado». 
segundo marido a la Virgen de Guadalupe. Atendiendo a los santos benefactores de su sobrina doña Luisa cuando esta dictó testamento, que por su crianza junto con los duques sus tíos y su intensa espiritualidad puede ofrecer bastantes indicios, se puede concluir que doña Ana le transmitió algunas de sus devociones. Las de los santos Juan Evangelista y Bautista parecen bastante claras por haberlo sido también de su padre el arzobispo don Alonso de Aragón; quizás a estas habría que añadir a María Magdalena si bien se trata de una conjetura. Aparte de la popularidad que tuvo la santa, podría ser posible que la duquesa le tuviera especial devoción.

Cuarto, cabe plantearse de hasta qué punto la duquesa pudo ser paradigmática de la espiritualidad de las mujeres del sur hispano a comienzos del siglo XVI; realmente nos decantamos por lo contrario. Teniendo unos orígenes distintos a los de otras nobles andaluzas del momento y sobre todo, unas experiencias vitales marcadamente más agitadas -desde su matrimonio en 1515 hasta la calma en los estados de Medina Sidonia comienzos de la década de 1520- no parece seguir el esquema que muchas otras. No pretendemos marcar la singularidad del personaje sino únicamente señalar el escaso interés que tuvo por la vida conventual tanto para sí como para sus hijas, ${ }^{35}$ algo que no se encontraba en los Guzmán, su familia de destino, pero sí en sus orígenes aragoneses.

Por último, un aspecto reseñable y común a todo el desarrollo de la vida espiritual de doña Ana de Aragón fue la presencia de esta en muchos de los aspectos de carácter religioso que se dieron en la casa ducal de Medina Sidonia. Si dirigió durante su vida buena parte de los asuntos terrenales de los Guzmán, lo mismo hizo con los espirituales para facilitar su salvación.

\section{Bibliografía}

Atienza López, Ángela. 2008. Tiempos de conventos: una historia social de las fundaciones en la España moderna. Madrid: Marcial Pons.

Bacon, Paul M. 2008. "Art patronage and piety in electoral Saxony: Frederick the Wise promotes the veneration of his patron, St. Bartholomew». The Sixteenth Century Journal 39: 973-1001.

Cabibbo, Sara. 1998. «Una santa en familia. Modelos de santidad y experiencias de vida (Italia, siglos XVII-XIX)». Studia Historica 19: 37-48.

Carrasco Martínez, Adolfo. 2000. «Los Mendoza y lo sagrado. Piedad y símbolo religioso en la cultura nobiliaria». Cuadernos de Historia Moderna 25: 233-269.

Crémoux, Françoise. 2015. Las edades de lo sagrado: los milagros de Nuestra Señora de Guadalupe y sus reescrituras (siglos XV-XVII). Zaragoza: Institución Fernando el Católico.

Cruz Isidoro, Fernando. 2002. "Vasco Pereira y la serie de seis retablos dominicos para la casa ducal de Medina Sidonia». Laboratorio de Arte 15: 357-364.

Cruz Isidoro, Fernando. 2011. «El convento de Santo Domingo de Sanlúcar de Barrameda: patronazgo de los Guzmanes, proceso constructivo y patrimonio artístico (1528-1605)». Laboratorio de Arte 23: 79-106.

Cruz Isidoro, Fernando. 2018. El monasterio de Madre de Dios. Historia y patrimonio artístico de las dominicas sanluqueñas. Sanlúcar de Barrameda: Monasterio de la Anunciación del Señor (vulgo Madre de Dios).

35 Entre las que incluimos a doña Luisa de Borja, que aunque no biológica, sí espiritual como ha quedado dicho.
Elipe, Jaime. 2017. «Aproximación a la figura de doña Ana de Aragón, duquesa de Medina Sidonia (ca. 1500-1556)». En Autoridad, poder e influencia. Mujeres que hacen historia, ed. Henar Gallego Franco y M. del Carmen García Herrero, 67-82. Barcelona: Icaria.

Elipe, Jaime. 2020. «Entre el amor y el temor divino: la religiosidad del arzobispo don Alonso de Aragón». En Elites políticas y religiosas, devociones y santos (siglos XVI-XVIII), ed. Eliseo Serrano Martín y Juan Postigo Vidal, 31-46. Zaragoza: Institución Fernando el Católico.

Gómez Fernández, Lucia. 2017. Música, nobleza y mecenazgo. Los duques de Medina Sidonia en Sevilla y Sanlúcar de Barrameda (1445-1615). Cádiz: Universidad de Cádiz.

Graña Cid, María del Mar. 2012. «Poder nobiliario y monacato femenino en el tránsito a la Edad Moderna (Córdoba, 1495-1550)». Cuadernos de Historia Moderna 37: 43-72.

Husftader, Anselm. 1969. «Lefèvre d'Étaples and the Magdalen». Studies in the Renaissance 16: 31-60. https://doi.org/10.2307/2857172

Jansen, Katherine L. 2000. "Like a virgin: the meaning of the Magadalen for female penitents of Later Medieval Italy». Memoirs of the American Academy in Rome 45: 131-152. https://doi. org $/ 10.2307 / 4238768$

King, Margaret L. y Albert Rabil Jr., eds. 2007. Teaching other voices. Women and religion in Early Modern Europe. Chicago: Chicago Universty Press.

Malo Barranco, Laura. 2017. «Los espacios de religiosidad y la devoción femenina en la nobleza moderna. El ejemplo de los linajes Aranda e Híjar». Cuadernos de Historia Moderna 42: 175-193.

Malo Barranco, Laura. 2018. Nobleza en femenino. Mujeres, poder $y$ cultura en la España moderna. Madrid: Centro de Estudios Políticos y Constitucionales.

Morte García, Carmen. 2008-2009. «Luisa de Borja y Aragón, duquesa de Villahermosa y condesa de Ribagorza. La familia Borja del siglo $\mathrm{XVI}$ en Aragón». Revista Borja. Revista de I'Institut Internacional d'Estudis Borgians 2: 483-527.

Nieva Ocampo, Guillermo. 2013. «Servir en la Corte de los Reyes Católicos: dominicos en los oficios de tutor de príncipes y embajador (1490-1516)». Revista chilena de estudios medievales 4: 63-76.

Nonell, Jaime. 1892. La santa duquesa. Vida y virtudes de la venerable y excelentísima señora doña Luisa de Borja y Aragón, condesa de Ribagorza y duquesa de Villahermosa. Madrid: Imprenta y Fundición de Manuel Tello.

Ortiz de Zúñiga, Diego. 1796. Anales eclesiásticos y seculares de la muy noble y muy leal ciudad de Sevilla, metrópoli de la Andalucía que contiene sus mas principales memorias desde el año 1246..., ilustrados y corregidos por D. Antonio Maria Espinosa y Carzel, vol. III. Madrid: Imprenta Real.

Pennman, Michael. 2013. "Sacred food for the soul": in search of the devotions to saints of Robert Bruce, King of Scotland, 13061329». Speculum 88: 1035-1062.

Pérez García, Rafael Mauricio. 2011. «Espirituales, cortes señoriales y linajes nobiliarios. Construcción y desarrollo de climas sacro-espirituales de referencia social en la Andalucía de los siglos XVI y XVII». Historia y Genealogía 1: 133-153.

Pons Fuster, Francisco. 2012. "Dos modelos culturales y religiosos. Juan de Borja y su hijo Francisco de Borja». En Francisco de Borja y su tiempo. Política, religión y cultura en la Edad Moderna, ed. Enrique García Hernán y María del Pilar Ryan, 167-187. Valencia Roma: Albatros - Institutum Historicum Societatis lesu.

Pons Fuster, Francisco. 2016. «Aproximación al estudio sobre el Modelo de mujer espiritual de los eclesiásticos en la Edad Moderna». Scripta. Revista internacional de literatura i cultura medieval i moderna 8: 268-286.

Roa, Martín de. 1604. Vida de doña Ana Ponce de Leon, condesa de Feria y despues monja en el monesterio de Santa Clara de Montilla. Córdoba: Viuda de Andrés Barrera.

Salas Almela, Luis. 2011. «Fundaciones conventuales en Sanlúcar de Barrameda: una imagen de poder señorial en el camino de los eclesiásticos a Indias (1492-1641)». Historia y genealogía 1: 189204. 
Sanctus Franciscus Borgia quartus Gandiae dux et Societatis lesu Praepositus Generalis Tertius. 1894. Vol. I. Madrid: Typis August.

Vidal Vargas, José María. 2018a. «Leonor Manrique de Sotomayor, regente de los estados de los Medina Sidonia y monja profesa en el convento de Madre de Dios de Sanlúcar de Barrameda». Tiempos modernos 37: 221-233.
Vidal Vargas, José María. 2018b. «Los duques de Medina Sidonia y las fundaciones de conventos en Sanlúcar de Barrameda: imagen y consolidación del poder señorial». En Nuevas perspectivas de investigación en Historia Moderna: Economía, Sociedad, Política y Cultura en el Mundo Hispánico, ed. María de los Ángeles Pérez Samper y José Luis Betrán Moya, 239-250. Madrid: FEHM. 
